\title{
A re-valuation of Glass's method of fractional precipitation of gastric secretion
}

\author{
J. SCHRAGER
}

From the Department of Pathology, Royal Albert Edward Infirmary, Wigan

SYNOPSIS The work of Glass has suggested that glandular mucoprotein and mucoproteose can be isolated by a fractional precipitation method from gastric secretion. These studies have failed to confirm this hypothesis and point out a fallacy of the original technique used.

Glass and Boyd (1948, 1949) published several papers describing in great detail a fractional precipitation method for estimating human gastric mucus secretion obtained on routine gastric aspiration (Fig. 1).

They claimed to have isolated from the dissolved mucin, two separate mucous substances:-1, Glandular mucoprotein, stated to be a homogeneous chemical compound closely associated with the intrinsic factor and secreted by a special group of cells, namely, the mucoid cells in the neck of the gastric glands situated in the body and fundus of the stomach (Glass and Boyd, 1949; Glass, 1953); 2, mucoproteose, a complex of intermediate products of digestion of gastric mucus (Glass and Boyd, 1949).

For the last 10 years Glass and his group have investigated the secretory patterns of glandular mucoprotein and mucoproteose in health and in patients with gastric lesions, and claimed to have obtained distinctive secretory patterns of diagnostic significance. These claims have been accepted by many other investigators, and have been quoted frequently in the medical literature dealing with gastric secretion (James, 1957; Kent and Whitehouse, 1955; Bettelheim-Jevons, 1958). The fractional precipitation method (Glass and Boyd, 1949) has been re-examined in our laboratory and the results indicate that the method was based on an erroneous assumption.

Glass and Boyd (1949) stated that pepsin is precipitated from the gastric secretion by the addition of $\frac{1}{2}$ volume of $10 \%$ trichloracetic acid. We have been unable to substantiate this. We found (Fig. 1, step 1) that pepsin was not precipitated by trichloracetic acid but remained in the supernatant; it is, in fact, precipitated by acetone (step 2), which at the same time brings down the mucopolysaccharides. The whole of the pepsin in the precipitate is redissolved on adding $0.1 \mathrm{~N} \mathrm{NaOH}$ and is reprecipitated on acidification (step 3).

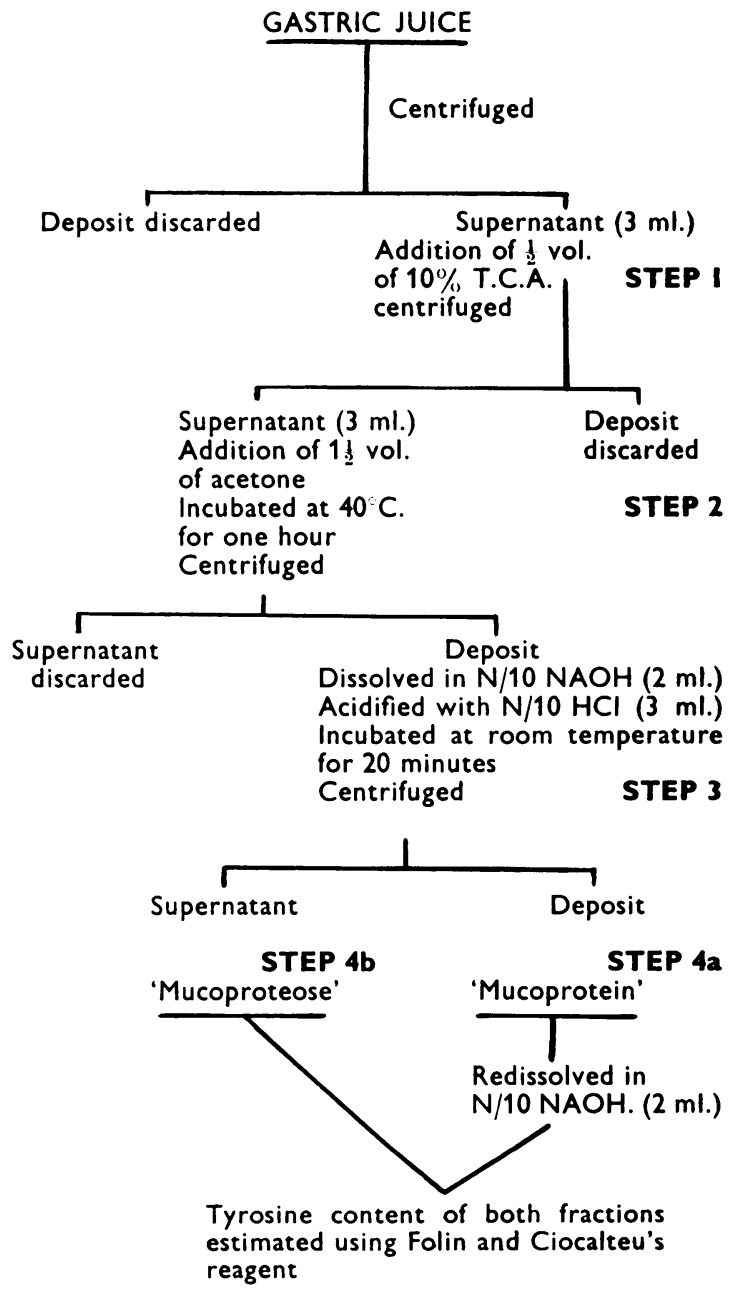

FIG. 1. Diagram of the fractional precipitation method of Glass for the isolation of gastric mucoproteose and mucoprotein. 

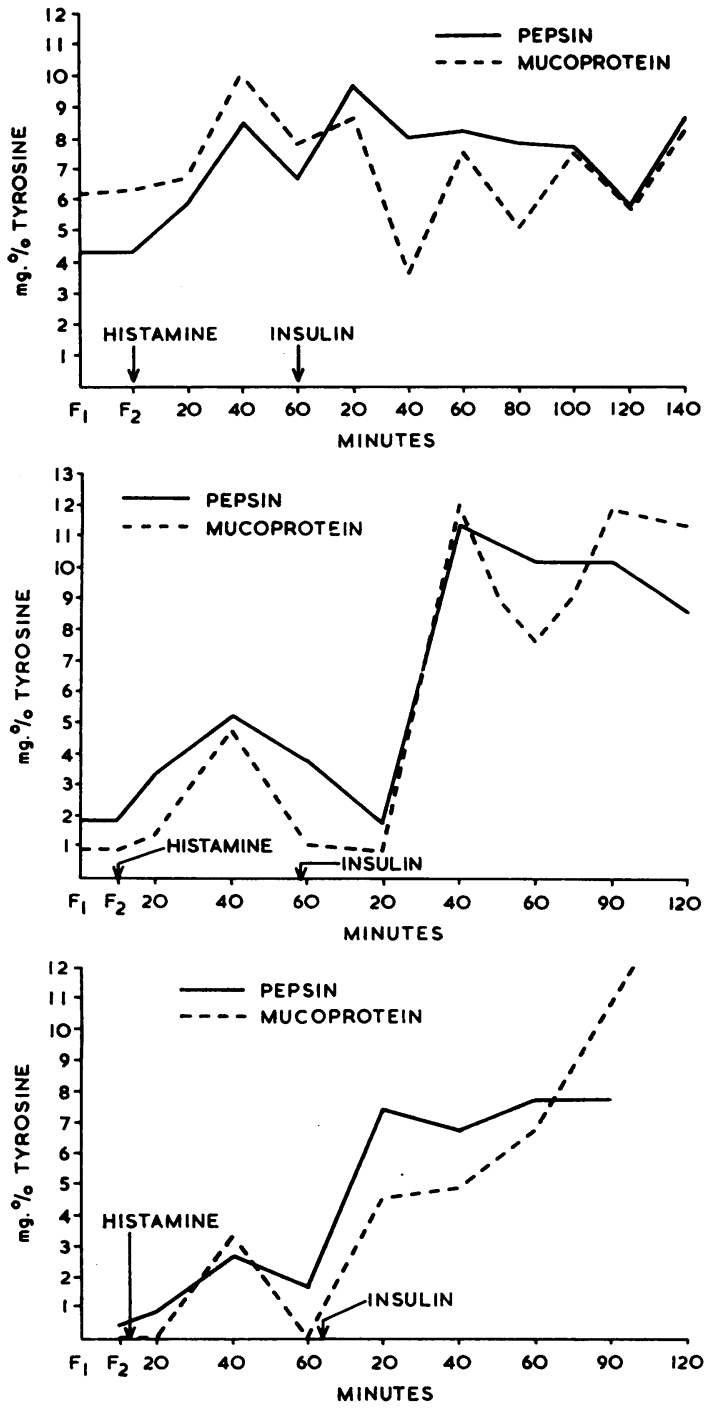

FIGS. 2-4. Results of fractional gastric analysis showing the glandular mucoprotein and pepsin content expressed as tyrosine.

\section{PROCEDURE AND RESULTS}

The following investigations were carried out in order to determine the nature of the precipitated materials obtained from gastric secretions by fractional precipitation.

Fractional gastric aspirations were carried out using histamine and insulin as stimulants. The procedure was as follows:-

Two fasting specimens were aspirated at 10-minute intervals followed by intramuscular injection of histamine acid phosphate, $0.04 \mathrm{mg}$. per $\mathrm{kg}$. body weight of the patient, followed by three aspirations at 20-minute intervals. The histamine injection was preceded by intramuscular injection of an antihistamine (mepyramine, $50 \mathrm{mg}$.). Intravenous insulin was then given, the dose depending on the fasting blood sugar (16 to 20 soluble units). Aspirations were carried out every 20 minutes; in two cases the last two specimens were aspirated at 30-minute intervals (Figs. 3 and 4). These fractional gastric aspirations were repeated on three patients. In each specimen the mucoprotein was estimated in terms of tyrosine, following Glass's procedure, and pepsin content was measured by its enzyme activity (Goodman's (1954) modification of West, Ellis, and Scott's (1952) method) using crystalline pepsin (Armour) as standard.

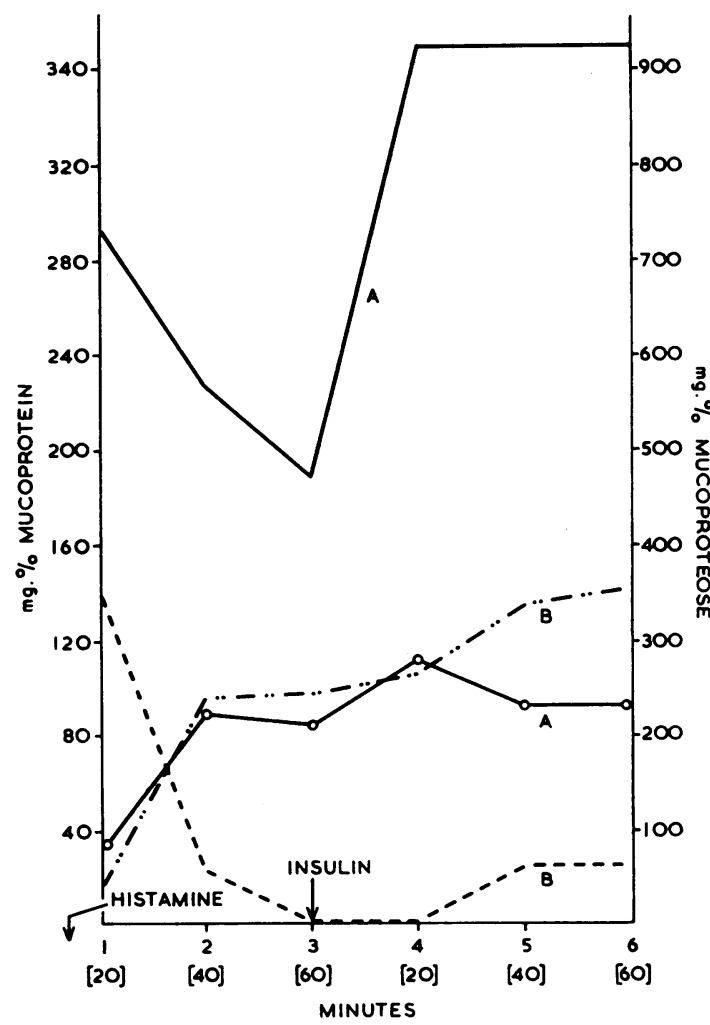

FIG. 5. Results of fractional gastric analysis after adding $100 \mathrm{mg} . \%$ pepsin to specimens 1,2 , and 3 , and after adding $200 \mathrm{mg} . \%$ to specimens 4,5 , and 6.

- - - - Mucoprotein before addition of pepsin Mucoprotein after addition of pepsin ....--+- Mucoproteose before addition of pepsin $\circ-0 \_0$ Mucoproteose after addition of pepsin

When the tyrosine content of the pepsin was calculated, on the basis of $9 \%$ (Block and Weiss, 1956), it was found to approximate to that derived from the 'glandular mucoprotein' (Figs. 2, 3, and 4). The gastric secretion had to be diluted $100-400$ times and the findings multiplied accordingly. In 


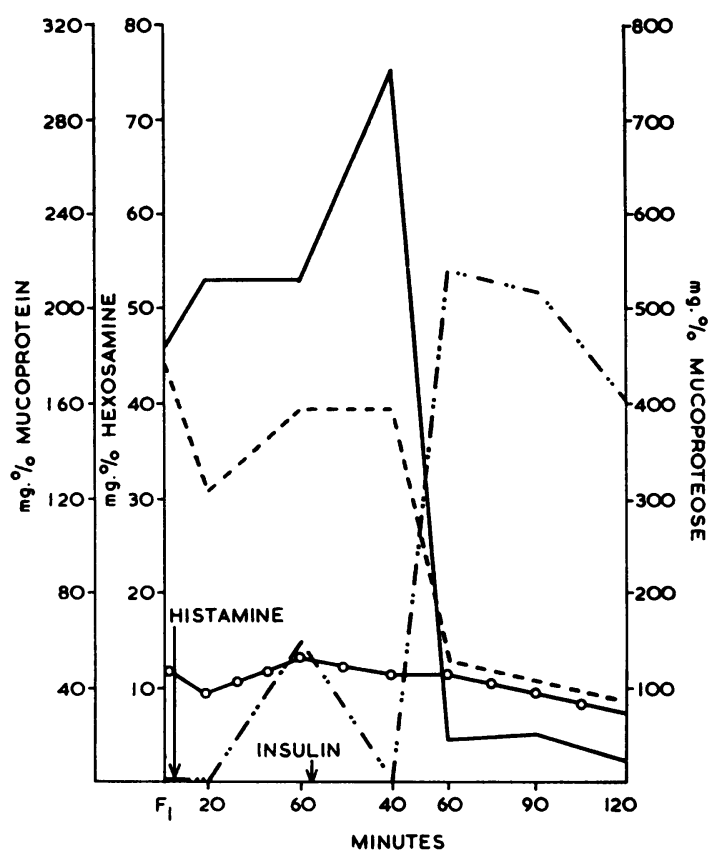

FIG. 6. Results of fractional gastric analysis showing mucoprotein and mucoproteose and their hexosamine content.

\begin{tabular}{l} 
Mucoproteose \\
\hline$-. .+\ldots-. .-$ Mucoprotein \\
$\circ-0-$ Hexosamine with mucoprotein \\
$-\ldots \ldots+-$ Hexosamine with mucoproteose
\end{tabular}

spite of all these manipulations we find the two curves running so closely that we are forced to the conclusion that Glass's glandular mucoprotein is mainly pepsin assayed from tyrosine content.

Fractional gastric aspirations were performed following the procedure described above. Two aliquot portions ( $A$ and $B$ ) were taken from each specimen. Varying quantities of pepsin were added to the specimens of set A (Fig. 5). No pepsin was added to the specimens of set $B$. The glandular mucoprotein and mucoproteose were estimated in all the specimens of sets $A$ and $B$.

The results show that the addition of pepsin increased the 'glandular mucoprotein', the increase being related to the amount of added pepsin. There was no increase in the mucoproteose.

This investigation appears to demonstrate conclusively that pepsin is the main source of the tyrosine used by Glass for estimating his 'glandular mucoprotein'.

Fractional gastric aspirations were performed as above. The glandular mucoprotein and mucoproteose were estimated as well as the hexosamine content of both these fractions. The results (Fig. 6) show no quantitative relationship between the glandular mucoprotein and the hexosamine content.
These data suggest that the precipitate does not consist of a single homogeneous and stoichiometric complex as would be expected of a pure mucoprotein. An investigation which is being carried on in our laboratory suggests that a sulphated mucopolysaccharide is precipitated together with a pepsin. The nature of this mucopolysaccharide is being studied. The larger portion of the hexosamine content of the gastric secretion was found in the supernatant (Fig. 1, step 4b). Here again no consistent quantitative relationship could be established between the tyrosine and the hexosamine content.

Our investigations suggest that the hexosamine is provided by a sulphated and non-sulphated mucopolysaccharide contained in the supernatant. Attempts are being made in this laboratory to isolate and study its substance.

\section{CONCLUSION}

Our findings do not support Glass's claim. The results warrant the conclusion that the tyrosine estimation used by Glass to calculate the 'mucoprotein' and 'mucoproteose' is a measure of the proteinous material only. The tyrosine of the 'mucoprotein' relates mainly to the pepsin content. Neither the 'mucoprotein' nor the 'mucoproteose' show even an approximately constant composition. It is suggested that this fractional precipitation scheme is not suitable for the isolation and determination of any mucoprotein or mucopolysaccharide secreted by the human gastric mucosa.

I wish to thank the Medical Research Sub-Committee of the Manchester Regional Hospital Board for a financial grant and encouragement. My thanks are also due to Mrs. M. Dodd and Mr. J. Howard for their technical assistance.

\section{REFERENCES}

Block, R. J., and Weiss, K. W. (1956). Amino Acid HandbookMethods and Results of Protein Analysis. Thomas, Springfield, Illinois.

Bettelheim-Jevons, F. R. (1958). Protein-carbohydrate complexes. Advanc. Protein Chem., 13, 35-105.

Glass, G. B. Jerzy (1953). Hematopoietic activity of glandular mucroprotein from human gastric juice. Gastroenterology, 23, 219-228.

$\longrightarrow$, and Boyd, L. J. (1948). Studies on dissolved mucin (mucoprotein) of the gastric juice. II. A new quantitative colorimetric method for the determination of total dissolved gastric mucin. Rev. Gastroent., 15, 511-519.

-_, - (1949). The three main components of the human gastric mucin: dissolved mucoproteose, dissolved mucoprotein, and mucoid of the gastric visible mucus. Gastroenterology, 12, 821-878. (Note $\mathrm{Pt} 3$ of article is on pp. 849-878.)

Goodman, R. D. (1954). J. Lab. clin. Med., 40, 872-879.

James, A. H. (1957). The Physiology of Gastric Digestion (Monogr. Physiol. Soc. No. 4). Arnold, London.

Kent, P. W., and Whitehouse, M. W. (1955). Biochemistry of the Amino-sugars. Butterworths, London.

West, P. M., Ellis, F. W., and Scott, B. L. (1952). A simplified method for determining the excretion rate of uropepsin. J. Lab. clin. Med., 39, 159-162. 